\title{
Explanations for Age Differences in SLA on Perspective of Sociolinguistics
}

\author{
Yan $\mathrm{Xu}$ \\ Foreign Language School \\ HuangHe Science and Technology College \\ e-mail: xuyan_25@163.com
}

\begin{abstract}
Age is one of factors which influence foreign language learning. However, social-psychology, as one of age-related factors, is the key to the different level between children and adults. In a review of Krashen's research, this paper mainly analyses age differences from sociolinguistics perspective. At the same time, this paper also proposes its weakness and explains age difference further with pragmatics and Vygotsky's theory of the zone of proximal development and implications for teaching second language.
\end{abstract}

Keywords—age differences; sociolinguistics; pragmatics; ZPD

\section{INTRODUCTION}

It is commonly known that children with regular faculties and given normal circumstances easily master their native language (L1). Unfortunately, perfect language mastery is rarely the result of second language acquisition. One of the central questions is why learners of a non-native language (L2) evince such a high degree of interindividual variation in their final attainment relative to the L2 components and skills they have acquired. In order to offer a satisfactory response to this key issue, SLA researchers have posited the existence of a set of individual factors of a very different nature, such as aptitude, motivation, attitude, personality, and intelligence, among others, that might explain such variation. However, one of the most obvious potential explanations for the lack of success of L2 learners compared to L1 learners is that the acquisition of a foreign language begins at a later age than that of the mother tongue does (cf.Larsen-Freeman / Long: 153). Thus, it has been prevalently assumed that age itself is a predictor of second language proficiency.

\section{KRAHEN'S INTERPRETATION OF AGE DIFFERENCES}

Long(1990) proposed four main types of explanation: (a)the language faculty is just as capable of learning L2s in order learners as in child learners, but 'affective' factors like threatened self-esteem, low EGO PERMEABILITY and perceived social distance act as a barrier between L2 data and the language faculty (Krahen,1982);(b) input to adult learners is less well-tuned than to children, so that older learners do not get they require to be fully successful;(c)COGNITIVE DEVELOPMENT (development of advanced thinking processes) somehow inhibits language learning ability(Krashen, 1982); (d) changes in the nature of the brain with age cause a decline in language learning ability. [1]
In spite of the predominance of psycholinguistics here, a wedge for sociolinguistic interpretation exists. In a review of the research, Krashen (1982), referring to Krashen, Long, and Scarcella (1979), notes three general areas of agreement among researchers:

(1) Adults proceed through the early stages of syntactic and morphological development faster than children (when time and exposure are held constant). [2]

(2) Older children acquire faster than younger children (again, in the early stages of syntactic and morphological development where time and exposure are held constant).

(3) Acquirers who begin natural exposure to second language during childhood generally achieve higher second language proficiency than those beginning as adults.

\section{A. Advantages}

Firstly, Krashen believes that the cerebral dominance theory is no longer supported by the evidence. Children do not acquire better because they have greater brain plasticity (a theory associated with Lenneberg 1967), for Krashen maintains that left-brain dominance is established well before puberty. Evidence from dichotic listening tests, motor skill observation, research with EEG and AER techniques, and the observation of morphological differences in the hemisphere even in the prenatal brain leads to that conclusion. If it is true, that should cast considerable doubt on the strong position that the acquisition of cerebral dominance at puberty is the principal differentiating factor in child-adult SLA (Krashen 1982:205-7). Krashen prefers to believe that the older child and adult advantaged in early language acquisitions is a direct result of cognitive superiority.

Secondly, if adults have an advantage in language acquisition due to some sort of formal operations superiority and children do not have any advantage due to greater brain plasticity, how may one explain the fact that eventual acquisition success is much greater for those who begin SLA at a younger age? Krashen agrees with Schumann(1975), who, after a review of literature on affective development, claims that 'language learning difficulties after puberty may be related to the social and psychological changes an individual undergoes at that age.' Specifically, according to Larsen and Smalley (1972): As puberty approaches and the individual is concerned with the consolidation of his personality, it 
apparently becomes more difficult for him to submit to the new norms which a second language requires. As an individual's dependence on others gives way to his own independence in satisfying needs, there seems to be less pull toward the internalization of new norms required by a second language.

Thirdly, Schumann (1975) cites findings which support the claim that adult and adolescent learners are more concerned with identity, less open to new people and customs, more suspicious of novelty, less malleable, and more threatened by situations in which they might appear ridiculous. Krashen (1982) takes all this to mean that adolescents and adults have an affective filter made up, at least in part, of suspiciousness and concern for identity; this filter removes comprehensible input from older learners' experiences and eventually causes them to lag behind the child, whose open and less ego-involved identity will ultimately lead to a more NS-like performance.

\section{B. Weaknesses}

Krashen's interpretation focuses on the elements of psychology of learners, however, there are some problems. Firstly, it ignores the role of language in constructing society. Secondly, the research in the areas of discourse and pragmatics should be done.

At first, age differences from a sociolinguistic perspective reflect two radically different processes. First, differences in generational speech may be indicators of language change. A strong claim in sociolinguistics is that change is not too slow to be observed. A new generation of speakers may reflect changes in the language, and historical linguistics may be done in living speech communities as well as in dusty tomes. Second, and this is tricky, age differences in a speech community may reflect age-grading rather than change. If, for example, teenagers use certain slang items, and give them up when they become adults, such items are age-graded, not predictors of language change. If older people use certain forms only when they become old, such forms are age-graded, not even indicators of what the language used to be, for, without further evidence, one may assume equally that the next generation of older speakers will behave in the same way or that they will behave in a novel way appropriate to their age group and that their performances will not be the same as the last generation of older speakers. In neither case would such age-graded performance have any influence on general language change.

Secondly, more recent work in both sociolinguistics and SLA focuses on the acquisition of language through pragmatic and interactional form and on the acquisition of the broader linguistic abilities known as communicative competence. [3]

Studies of conversations between NSs and NNSs show that discourse rules vary according to the age of the NNS interlocutor. Hatch (1978) observes that conversational learning in L2 is very like that in L1: SLA child acquirers use attention getters to open conversations, nominate or initiate topics, and so on. One of the more intriguing aspects of conversation which has been proposed in the psycholinguistic literature is that syntactic learning is a by-product of conversation. That is, the vertical combinations of turns in conversations are first language learners' early cues to the propositional structure of sentences.

The NNSs differed by age in their conversational strategies. The adolescent subjects (1) used more comprehension checking devices, (2) provided comments on NS introduced topics more frequently than younger children, (3) repeated utterances less frequently than younger children, (4) initiated new topics or shifted topics more frequently than younger children, and (5) used more conversational fillers (for example, 'let's see' and 'uhm' ) than younger children.

\section{ZONE OF PROXIMAL DEVELOPMENT}

Vygotsky (1978) maintained the child follows the adult's example and gradually develops the ability to do certain tasks without help or assistance. He called the difference between what a child can do with help and what he or she can do without guidance the "zone of proximal development" (ZPD). Children's learning is greatly influenced by the social context for learning. Vygotsky (1962) argues that learning language is a social phenomenon. From the beginning, children are engaged in communicating with others, a quintessentially social process. It therefore behooves you to create a learning community using strategies like the ones given in the teaching idea: Building a classroom community. [4]

\section{IMPLICATIONS FOR TEACHING SECOND LANGUAGE}

The purpose to analyze the age differences from sociolinguist perspective is to use linguistic analysis to work towards a solution to shortcomings in education. Nowadays, our school curricula have traditionally presupposed standard language, ignoring the fact that the standard is accorded preferred status for social reasons alone and is hence close to the speech of some children than to that of others. Therefore, we should create an atmosphere where students feel a sense of community and where they feel free to ask for help and take risks. A classroom that is socially and emotionally supportive has a generally friendly atmosphere. It is a safe and caring place for all learners, regardless of their cultural or linguistic backgrounds or their abilities.

\section{CONCLUSION}

This paper mainly analyzes the causes of the age differences from sociolinguistics perspective and its implications for teaching second or foreign language. Although there are some evidences to prove the age differences from sociolinguistics perspective, there still exists the theoretical deficit of sociolinguistics, because Krashen's research ignores the role of language in constructing society and the importance of discourse and pragmatics. Therefore, the theory of the age differences should be invested further.

\section{REFERENCES}

[1] Keith Johnson. Encyclopedic Dictionary of Applied Linguistics: A Handbook for Language Teaching[M].Beijing : Foreign Language Teaching and Research Press, 2001

[2] Michael $\mathrm{H}^{\cdot}$ Long. An Introduction to Second Language Acquisition Research [M]. Beijing: Foreign Language Teaching and Research Press, 2000 
[3] Dennis R· Preston. Sociolinguistics and Second Language Acquisition [M]. Britain :Basil Blackwell Press, 1989

[4] Dorothy S S Strickland. Learning Art : . Learning and Teaching [M].Beijing: Beijing University Press, 2005 